\title{
BIOCHEMICAL, NUTRIENT AND INHIBITORY CHARACTERISTICS OF STREPTOMYCES CULTURED FROM A HYPERSALINE ESTUARY, THE LAGUNA MADRE (TEXAS)
}

\author{
${ }^{1}$ Luis E. Espinoza, ${ }^{1,2}$ Anita L. Davelos Baines and ${ }^{1}$ Kristine L. Lowe \\ ${ }^{1}$ Department of Biology, University of Texas-Pan American, Edinburg TX 78539, USA \\ ${ }^{2}$ Department of Biology, University of Wisconsin La Crosse, La Crosse WI 54601, USA
}

Received 2013-02-14; Revised 2013-04-27; Accepted 2013-05-07

\begin{abstract}
Streptomyces are common soil bacteria that produce secondary metabolites, including several antibiotics; however, the characteristics of marine Streptomyces are largely unknown. Sediment samples were taken from 3 sites in the Laguna Madre to isolate marine Streptomyces. Sediment was diluted, spread onto synthetic seawater media to estimate the total bacterial density of the samples and spread onto starch casein agar to isolate Streptomyces. Isolated Streptomyces were tested for salinity tolerance and optimal growth $\mathrm{pH}$. Isolates were assayed using API $20 \mathrm{E}^{\circledR}$ test strips and $\mathrm{BIOLOG}^{\mathrm{TM}}$ plates to construct biochemical profiles and assess nutrient utilization abilities of the bacteria, respectively. Individual Streptomyces were tested for the ability to inhibit the growth of other isolated Streptomyces (i.e., interference competition) and putatively identified by DNA sequencing. Results showed that there was no significant difference in microbial density in sediments from the 3 sampling sites. Eleven (11) Streptomyces pure cultures were obtained in total; most tolerated salinity up to $60 \mathrm{ppt}$ and grew optimally at $\mathrm{pH} 7.5$. Biochemical profile comparisons showed that the Streptomyces were only at least $74 \%$ similar; most $(8 / 11)$ were $>90 \%$ similar. Isolates could use between 87-95 carbon sources. Three (3) isolates displayed interference toward other isolates. Ten (10) isolates were identified as Streptomyces griseus by DNA sequencing. Laguna Madre Streptomyces organisms display some diverse characteristics with regards to their halotolerance, biochemical profiles, carbon source utilization and inhibition toward other organisms. Further investigations may yield greater understanding of these organisms in this and other marine environments and may be a reservoir of novel microorganisms and secondary metabolites.
\end{abstract}

Keywords: Streptomyces, Bacteria, Laguna Madre, Hypersaline

\section{INTRODUCTION}

The genus Streptomyces is a diverse group of more than 500 species of Gram-positive, spore-forming, high $\mathrm{G}+\mathrm{C}$ bacteria within the phylum Actinobacteria. Streptomycetes produce networks of long-chain filaments that resemble the mycelia produced by fungi but are true bacteria and common inhabitants of terrestrial soils. Streptomycetes have been reported to represent a large percentage (10-28\%) of the bacteria of some soils (Barton and Northrup, 2011). A few members of the genus are plant pathogens; however, streptomycetes are best known for their production of secondary metabolites such as pigments and a variety of antimicrobial compounds that have been shown to inhibit the growth of other microorganisms (Madigan et al., 2000).

Although streptomycetes are abundant in soils, their occurrence, distribution and ecology in other environments, such as aquatic ecosystems, is not as well

Corresponding Author: Kristine L. Lowe, Department of Biology, University of Texas-Pan American, Edinburg TX 78539, USA Tel: 01 (956) 665-8749 
known. Members of the genus Streptomyces have been described as occurring widely in lake water (Rheinheimer, 1992) and marine streptomyetes have also been isolated (Jensen et al., 1991; Moran et al., 1995; Mincer et al., 2002). There are still many marine ecosystems that have not been explored for streptomycetes. In light of the vast secondary metabolism of streptomycetes, aquatic environments and marine ecosystems may be new sources of novel products produced by these bacteria.

The Laguna Madre is a shallow, hypersaline estuary in South Texas (USA) and Northern Mexico. Because it is partially land-locked between the Texas mainland and barrier islands in the Gulf of Mexico, high salt concentrations develop in the lagoon as a result of high evaporation rates and limited freshwater inputs (Tunnell and Judd, 2002). The Laguna Madre has an average depth of approximately $1.5 \mathrm{~m}$ and salinity of approximately $40 \mathrm{ppt}$. The Laguna Madre is along the migration route of several migratory and endangered species of birds and the macroecology of the ecosystem has been studied for decades. The microbial ecology of the Laguna Madre is largely undescribed.

The Laguna Madre may be a potential source of previously unstudied streptomycetes and streptomycetes isolated from the Laguna Madre may produce novel compounds or provide insights into the ecology of aquatic Streptomyces species that have been hitherto unknown. In this study, we sought to successfully isolate Streptomyces species from sediments of the Laguna Madre and characterize the isolated organisms using biochemical and nutrient utilization assays, inhibition experiments and DNA sequencing.

\section{MATERIALS AND METHODS}

\subsection{Study Site and Sample Collection}

Sediment samples were taken from 3 sites in the Laguna Madre, a hypersaline estuary in South Texas, in June 2006. Samples (approximately $50 \mathrm{~g}$ ) were collected from the top $10 \mathrm{~cm}$ of sediment. The sample locations were along a north to south transect. The sample locations were designated LMT056 [N26 30'42.1", W97 22'23.6"], LMT055 [2627'46.5", W97²1'51.2"] and SB [N26 $\left.02^{\prime} 48^{\prime \prime}, \mathrm{W} 97^{\circ} 11^{\prime} 3.3^{\prime \prime}\right]$. Samples LMT056 and LMT055 were closer in proximity to each other compared to sample SB, which was approximately $150 \mathrm{~km}$ south of the other sample sites. Samples were transported on ice to the University of Texas-Pan American Coastal Studies Lab on South Padre Island, Texas, USA and processed within $6 \mathrm{~h}$ of collection. Water temperature, $\mathrm{pH}$ and salinity were measured at the time of collection using a standard thermometer, a handheld $\mathrm{pH}$ meter and a handheld refractometer, respectively.

\subsection{Culturing and Population Density}

Ten-fold serial dilutions of sediment were made in Phosphate-Buffered Saline (PBS) Sambrook and Russell (2001) adjusted to $\mathrm{pH}$ 8. An aliquot of $100 \mu \mathrm{L}$ of the diluted sample was spread onto a synthetic marine medium, Marine 2216 (Difco/BBL, Detroit MI) and Starch Casein Agar (SCA). Marine 2216 agar was used to estimate the total culturable microbial density of the sediment samples. SCA was only used to isolate members of the genus Streptomyces (Kuster and Williams, 1964); the density of Streptomyces in the samples was not determined. SCA was amended with 30 $\mathrm{g} \mathrm{NaCl} \mathrm{L}^{-1}$ to enhance marine Streptomyces growth. All media contained pentachloronitrobenzene (PCNB) at a final concentration of $1 \mathrm{~g} \mathrm{~L}^{-1}$ to minimize fungal contamination. Cultures were grown for 3-4 days in an incubator at $28^{\circ} \mathrm{C}$. After incubating, the density of the microbial community was estimated by multiplying the number of colonies that arose on the agar plate by the dilution. Microbial density was reported as colony forming units per gram (cfu per gram) wet sediment.

\subsection{Streptomyces Quantification}

Colonies exhibiting characteristic streptomycete colony morphology (Bowers et al., 1996) on SCA were selected for further study. Streptomyces isolated from the Laguna Madre were inoculated onto Oatmeal Agar (OA) plates and allowed to grow for 4 days at $28^{\circ} \mathrm{C}$. The composition of OA plates was per liter: $40 \mathrm{~g}$ of ground Quaker Oats ${ }^{\circledR}$ oatmeal, $15 \mathrm{~g}$ Bacto agar and $1 \mathrm{~g}$ casamino acids (Anderson and Wellington, 2001). The isolates were then transferred into sterile cryotubes containing 2 $\mathrm{ml}$ of $20 \%$ glycerol to create working spore suspensions of each of the marine Streptomyces isolates. Each isolate was diluted to approximately $4.5 \times 10^{6}$ spores $/ \mathrm{mL}$. Suspensions were quantified by measuring the $\mathrm{OD}_{600}$ using a spectrophotometer. The spore suspensions were used in salinity, $\mathrm{pH}$ and inhibition experiments.

\subsection{Salinity and pH Assays}

Streptomyces isolated from the Laguna Madre were assayed for their salinity and $\mathrm{pH}$ tolerances. SCA plates were made with seven salt concentrations $(0 \mathrm{ppt}, 5 \mathrm{ppt}$, $30 \mathrm{ppt}, 40 \mathrm{ppt}, 60 \mathrm{ppt}, 90 \mathrm{ppt}$ and $120 \mathrm{ppt}$ ) by adding the appropriate amount of $\mathrm{NaCl}$ prior to autoclaving. All media was adjusted to $\mathrm{pH}$ 8.0. Streptomyces isolates were grown in triplicate on separate plates by dotting 10 
$\mu \mathrm{l}$ of quantified stock spore solution on each of the seven salinity plates. Cultures were incubated at $28^{\circ} \mathrm{C}$ for 3 days. A subjective scale was used to determine salinity tolerance based on ["No growth" or "Visible growth"] of the Streptomyces isolates.

The $\mathrm{pH}$ of SCA was adjusted with lactic acid or $\mathrm{NaOH}$ pellets to the following $\mathrm{pH}$ values: $6.8,7.0,7.3$, $7.5,7.8,8.0$ and 8.2. Streptomyces isolates were dotted (10 $\mu \mathrm{L}$ of quantified spore suspensions) on plates of the different $\mathrm{pH}$ values. Cultures were incubated at $28^{\circ} \mathrm{C}$ for 3 days. Assays were performed in triplicate. A subjective scale was used to rate the growth of the isolates (e.g., weak/little growth, fair growth, good growth and excellent growth).

\subsection{API $20 \mathrm{E}^{\circledR}$ Strips}

Biochemical profiles for Streptomyces isolates were generated using API $20 \mathrm{E}^{\circledR}$ test strips (bioMérieux Inc., Durham, NC). API $20 \mathrm{E}^{\circledR}$ strips include enzymatic tests for the fermentation or oxidation of glucose, mannitol, inositol, sorbitol, rhamnose, saccharose, melibiose, amygdalin and arabinose, along with nitrate reduction to nitrite and nitrate reduction to nitrogen gas. API $20 \mathrm{E}^{\circledR}$ strips also test for the presence of $\beta$-galactosidase, arginine dihydrolase, lysine decarboxylase, ornithine decarboxylase, citrate utilization, $\mathrm{H}_{2} \mathrm{~S}$ production, urease, tryptophan deaminase, indole production, acetoin production (Voges-Proskauer) and gelatinase. API $20 \mathrm{E}^{\circledR}$ tests were performed according to the manufacturer's instructions. The number and types of positive tests were tabulated for the isolates and used to construct biochemical phenotype profiles of the cultures which were compared amongst the isolates. A similarity dendogram among profiles was constructed using the program NTSYSpc (Exeter Software, Setauket, NY).To construct the similarity dendogram, an input matrix was constructed with the 22 API $20 \mathrm{E}^{\circledR}$ tests. If a bacterial isolate was positive for that test, the matrix input was ' 1 '. If the isolate was negative for the test, the matrix input was ' 0 '. The NTSYSpc software was then used according to the manufacturer's instructions to produce a similarity matrix and tree. Each isolate's profile was compared to the profile of all the other isolates and reported as a Coefficient of Similarity on a scale of 0.00 1.00 with 1.00 equal to $100 \%$ similarity.

\subsection{BIOLOG ${ }^{\mathrm{TM}}$ Carbon Source Utilization}

Nutrient (carbon source) utilization profiles were determined for the Streptomyces isolates using BIOLOG SFP2 ${ }^{\mathrm{TM}}$ plates. BIOLOG SFP2 ${ }^{\mathrm{TM}}$ plates were 96 well plates that have 95 carbon sources and a water control.
Spore suspensions for each isolate were made in $0.2 \%$ Carrageenan (Sigma, St. Louis MO) by harvesting an inoculated $\mathrm{OA}$ plate after 8 days growth at $28^{\circ} \mathrm{C}$. Spore concentrations were adjusted to an optical density of $0.22-0.24$ at $590 \mathrm{~nm}$. The adjusted spore suspension (1.5 $\mathrm{mL}$ ) was diluted in $13.5 \mathrm{~mL}$ of $0.2 \%$ Carrageenan and $100 \mu \mathrm{L}$ of the resulting suspension was inoculated into each well of the BIOLOG SFP2 ${ }^{\mathrm{TM}}$ plate using an eight channel micropipettor. Plates were incubated at $28^{\circ} \mathrm{C}$. At $48 \mathrm{~h}$, plates were measured using the BioRad $^{\circledR}$ Model 680 microplate reader. The absorbance of each well at an optical density of $590 \mathrm{~nm}$ was recorded. The test was performed in duplicate BIOLOG SFP2 ${ }^{\mathrm{TM}}$ plates for each isolate. The absorbance of the water control well was was subtracted from absorbances for each of the 95 carbon sources to account for background interference. Mean absorbance values for each substrate were calculated and negative mean absorbances were set to zero for subsequent analyses. Substrate richness was determined for each isolate (Zak et al., 1994; Vahjen et al., 1995). Substrate richness was defined as the total number of substrates with a positive mean absorbance value. A similarity dendogram among profiles was constructed as described above. Correspondence between similarity matrices for API and BIOLOG ${ }^{\mathrm{TM}}$ results was evaluated using Mantel's test (NTSYSpc; Exeter Software, Setauket, NY).

\subsection{Interference Competition Assays}

The ability of each Streptomyces isolate to inhibit and resist all others in the collection was evaluated following the methods of Davelos et al. (2004a). An aliquot $(10 \mu \mathrm{L})$ of each of the quantified Streptomyces spore suspensions were dotted onto SCA plates and allowed to grow at $28^{\circ} \mathrm{C}$. After three days, plates were turned over $4 \mathrm{~mL}$ of chloroform in a watch glass for $1 \mathrm{~h}$ in a fume hood to kill the isolate. Then the plates were allowed to vent dry for $30 \mathrm{~min}$ in a laminar flow hood. After venting dry, each plate had $15 \mathrm{~mL}$ of $1 \%$ water

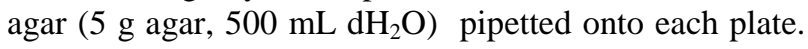
Once solidified, $100 \mu \mathrm{L}$ of one isolate was spread over the water agar layer and allowed to grow at $28^{\circ} \mathrm{C}$ for 3 days. This experiment was performed in all possible pair wise combinations for each the Streptomyces isolates. Each combination was replicated three times to ensure that observed results were not due to chance. Since all zones of inhibition observed did not have a uniform circular appearance, the mean zone of inhibition was obtained by taking the average of the largest and smallest points of the inhibition zone. All data were analyzed by taking the mean of the three replicated plates. 


\subsection{DNA Extraction and Sequencing}

DNA was extracted from the Streptomyces isolates using a commercial kit for Gram-positive bacteria (Wizard Genomic DNA Purification Kit; Promega, Madison WI) according to the manufacturer's instructions. Extracted DNA was verified by electrophoresis using 1\% agarose gels. Genomic DNA concentration was quantified by reading the absorbance in a UV-VIS spectrophotometer at $260 \mathrm{~nm}$. Purity of the extracted DNA was determined by the ratio of the absorbances at 260 and $280 \mathrm{~nm}$. Ratios of 260/280 absorbance measurements were between 1.7 and 2.0 for all samples; thus, the extraction yielded mostly DNA (Sambrook and Russell, 2001).

Molecular identification of the isolated bacteria was performed by the Polymerase Chain Reaction (PCR) amplification and sequencing of the $16 \mathrm{~S}$ ribosomal RNA (16S rRNA) genes (Sambrook and Russell, 2001) using primers designed for Streptomyces. Streptomyces specific primers SSU139F (5'ACAAGCCCTGGAAACGGGGT-3') and SSU657R (5'-CACCAGGAATTCCGATCT-3') located at positions 139-158 and 640-657 (S. ambofaciens numbering) were used (Malkawi et al., 1999). PCR reaction mixtures $(25 \mu \mathrm{L})$ consisted of $50 \mathrm{ng}$ of DNA, 10 nmol of each primer and PCR Promega ${ }^{\circledR}$ GoTaq $^{\mathrm{TM}}$ SuperMix. PCR was performed with a BioRad $^{\circledR}$ MyCyclerTM thermal cycler following the Takeuchi et al. (1996) protocol. Amplified PCR products were purified with the QIAquick PCR purification kit following the manufacturer's instructions (QIAGEN Inc., Valencia, CA). A second round of PCR was done for sequencing using a commercially-available sequencing kit (Genome Lab DTCS Quick Start Kit; Beckman Coulter, Fullerton $\mathrm{CA}$ ) according to the manufacturer's instructions and the SSU139F primer. Dye-tagged dideoxynucleotides (ddUTP, ddGTP, ddCTP and ddATP) were added to terminate elongation (Sambrook and Russell, 2001). The resulting PCR product was loaded into an automated DNA sequencer (CEQ 8000 Genetic Analysis System; Beckman Coulter, Fullerton, CA). The sequences were compared to known bacterial sequences available in the National Center for Biotechnology Information Basic Local Alignment Search Tool (BLASTN) database to identify the microorganisms (Altschul et al., 1997).

\section{RESULTS}

The salinity and $\mathrm{pH}$ of the Laguna Madre samples were as follows: LMT056, salinity $29.8 \mathrm{ppt}$ and $\mathrm{pH}$ 8.87; LMT055, salinity 30.5 ppt and $\mathrm{pH}$ 8.63; SB, salinity 32.4 and $\mathrm{pH}$ 8.9. The estimated density of the total culturable microbial populations grown on Marine
2216 agar at each site were not statistically different (Fig. 1). A total of 11 distinct Streptomyces isolates were cultured from SCA plates. Of the 11 isolates, 5 were from LMT056, 1 was from LMT055 and 5 were from SB (Table 1). The 11 Streptomyces were characterized physiologically and genetically.

The majority of Streptomyces isolates displayed a maximum growth salinity of $60 \mathrm{ppt}$ and a $\mathrm{pH}$ growth optimum of 7.5 (Table 1). With regards to salinity, the lowest salinity maximum was observed in isolate 56.2 which did not grow above $40 \mathrm{ppt} \mathrm{NaCl}$. The $\mathrm{pH}$ optima for 2 isolates, 56.2 and SB.5, were slightly higher; these isolates grew best at $\mathrm{pH} 7.8$ but did display growth at other $\mathrm{pH}$ values. Isolate 56.1 was the most halotolerant $(120 \mathrm{ppt})$ and alkalitolerant of the 11 isolates (8.0) (Table 1).

The 11 cultured Streptomyces isolates were screened for biochemical phenotypes using API $20 \mathrm{E}^{\circledR}$ test strips. A suite of 22 tests was used to construct a phenotype profile for each isolate. The number of positive tests displayed by the isolates ranged from 3-11 (Table 2). All 11 Streptomyces isolates showed an $\mathrm{API}^{\circledR}$ profile similarity coefficient of at least 0.74 meaning that their profiles were at least $74 \%$ similar (Fig. 2). Eight of the 11 isolates displayed greater than $90 \%$ similarity when profiled with API 20E test strips and 2 isolates, 56.1 and 55.1 , had identical profiles. Results of carbon source utilization based on BiOLOG ${ }^{\mathrm{TM}}$ assays are shown in Fig. 3. The number of carbon sources utilized ranged from 87-95. All 11 of the Streptomyces isolates had a minimum carbon source utilization similarity of 0.91 or $91 \%$. Several isolates had identical profiles. Isolate SB.5 utilized the lowest number of carbon sources (87) and displayed the least similarity to the other isolates (Fig. 3). Mantel's test showed that there was no correspondence between $\mathrm{API}^{\circledR}$ and BIOLOG ${ }^{\mathrm{TM}}$ phenotypes $(\mathrm{r}=0.12$, $\mathrm{p}>0.05)$.

The 11 Streptomyces isolates were examined for interference competition toward the other isolates. Interference competition plate assays were performed to determine whether an isolate could inhibit the growth of other isolates. A representative plate assay is shown in Fig. 4. Only 3 of the 11 Streptomyces strains could inhibit other isolates and eight isolates were resistant to inhibition by other isolates (Table 3). Isolate 55.1 was inhibitory toward isolate 56.1, isolate SB.3 could inhibit isolate SB.1 and isolate SB.4 could inhibit growth of isolates 56.1 and 56.5. These three inhibitory isolates were also resistant to inhibition by all other isolates. All other combination failed to produce inhibited growth. The five isolates from location LMT056 did not inhibit any other isolates; however two of these isolates were susceptible to inhibition from the other locations (Table 3). 
Luis E. Espinoza et al. / OnLine Journal of Biological Sciences 13 (1): 18-27, 2013

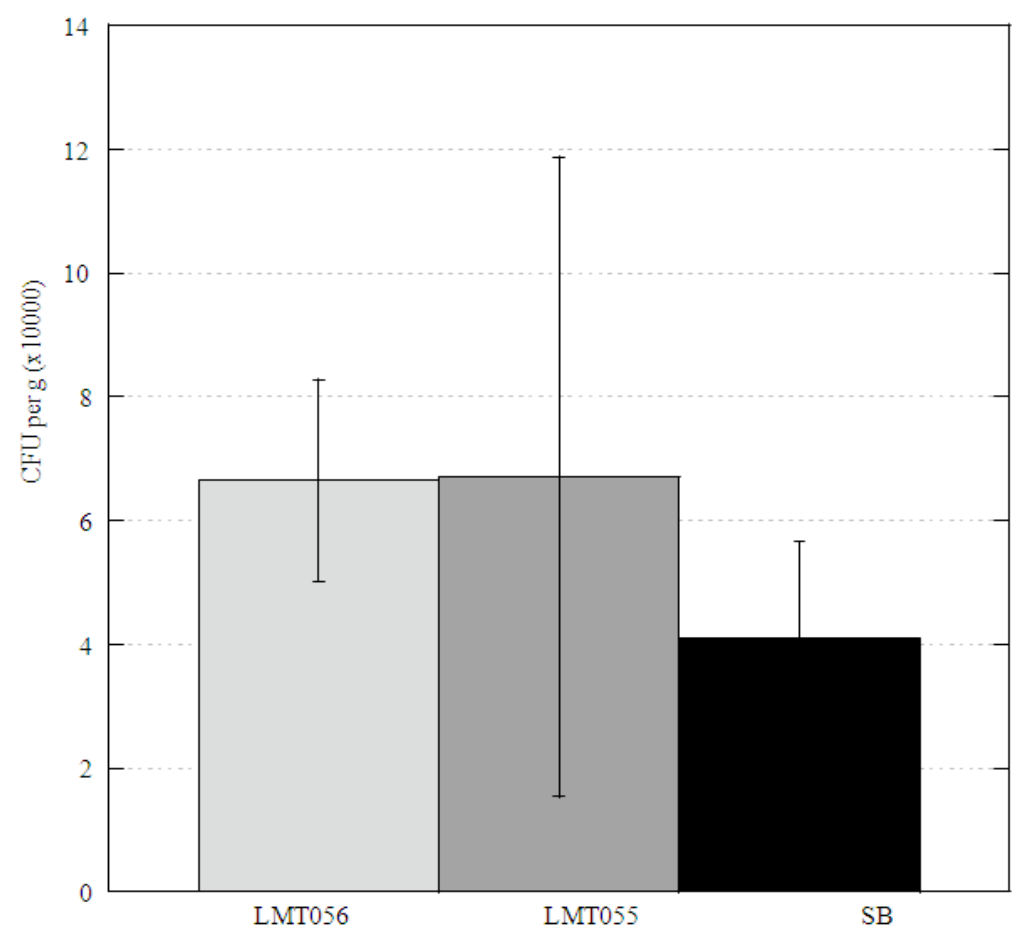

Fig. 1. Estimated density of bacteria in Laguna Madre sediment samples collected in June 2006. Sediment was diluted and spread on Marine 2216 agar. Values are reported as colony forming units per gram (cfu per gram $\times 10,000)$ wet sediment. Shown are the means of triplicate incubations with standard deviation

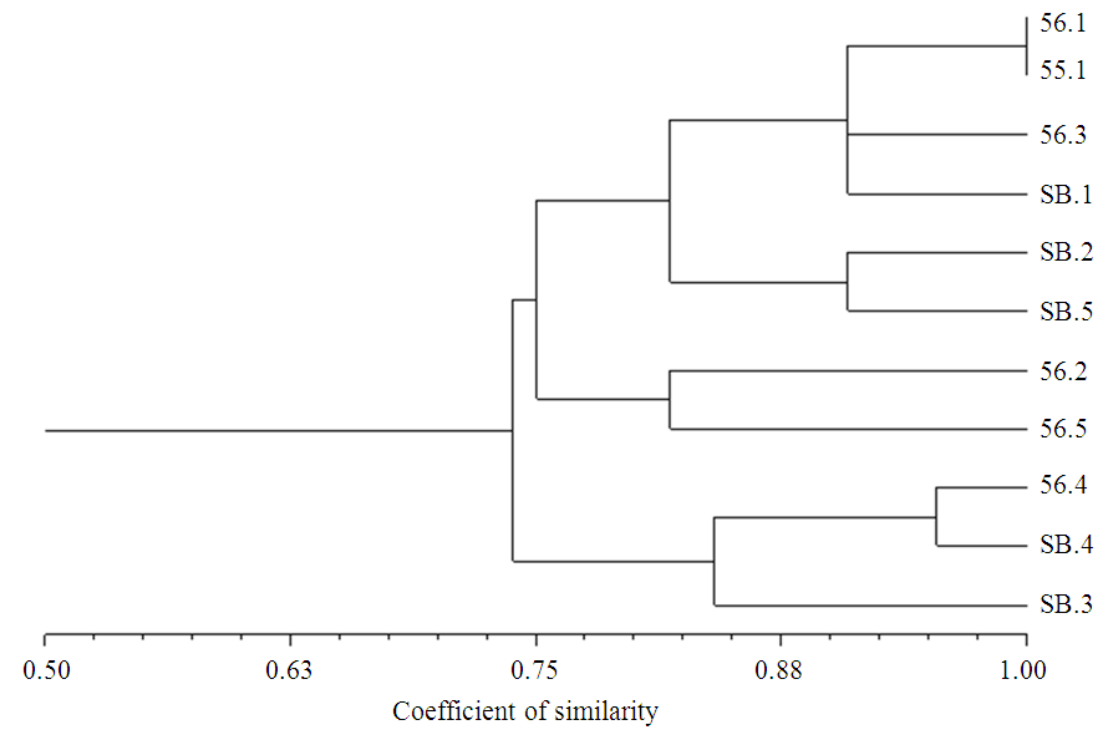

Fig. 2. Similarity of cultured Streptomyces microorganisms from the Laguna Madre based on API $20 \mathrm{E}^{\circledR}$ phenotype profiles.A total of 22 different enzymatic reactions were assayed using API $20 \mathrm{E}^{\circledR}$ strips. Based on the number of positive tests and which of the 22 tests were positive, a phenotype profile was created and compared to the profile of all other tested isolates. The similarity coefficient is shown on the $\mathrm{x}$-axis 
Luis E. Espinoza et al. / OnLine Journal of Biological Sciences 13 (1): 18-27, 2013

Table 1. Characterization and identification of Streptomyces isolates from the Laguna Madre. Salinity and pH tolerances were based on agar plate assays. Isolates were identified by sequencing of the 16S rRNA gene and comparing the sequencing to known sequences in the BLASTn database. The percent sequence match is shown

\begin{tabular}{llllll}
\hline $\begin{array}{l}\text { Isolate } \\
\text { designation }\end{array}$ & $\begin{array}{l}\text { Site of } \\
\text { Origin }\end{array}$ & $\begin{array}{l}\text { Maximum Growth } \\
\text { Salinity (ppt) }\end{array}$ & $\begin{array}{l}\text { pH Growth } \\
\text { Optimum }\end{array}$ & $\begin{array}{l}\text { Identity by 16S } \\
\text { rDNA sequencing }\end{array}$ & $\begin{array}{l}\text { ID } \\
\text { Match (\%) }\end{array}$ \\
\hline 56.1 & LMT056 & 120 & 8.0 & Streptomyces griseus & 97 \\
56.2 & LMT056 & 40 & 7.8 & Streptomyces griseus & 96 \\
56.3 & LMT056 & 60 & 7.5 & Streptomyces scabiei & 94 \\
56.4 & LMT056 & 60 & 7.5 & Streptomyces griseus & 98 \\
56.5 & LMT056 & 60 & 7.5 & Streptomyces griseus & 99 \\
55.1 & LMT055 & 60 & 7.5 & Streptomyces griseus & 93 \\
SB.1 & SB & 60 & 7.5 & Streptomyces griseus & 98 \\
SB.2 & SB & 60 & 7.5 & Streptomyces griseus & 99 \\
SB.3 & SB & 60 & 7.5 & Streptomyces griseus & 98 \\
SB.4 & SB & 60 & 7.5 & Streptomyces griseus & 99 \\
SB.5 & SB & 60 & 7.8 & Streptomyces griseus & 95 \\
\hline
\end{tabular}

Table 2. Biochemical (API) profiles of Streptomyces bacteria from the Laguna Madre. Eleven (11) Streptomyces isolates were isolated from the Laguna Madre sediment. The isolates' metabolic activities were tested using API $20 \mathrm{E}^{\circledR}$ strips. A plus sign $(+)$ indicates that the isolate was positive for the test; a negative sign (-) indicates a negative reaction for the test Isolate

\begin{tabular}{|c|c|c|c|c|c|c|c|c|c|c|c|}
\hline \multirow[b]{2}{*}{ Test } & \multicolumn{11}{|c|}{ Isolate } \\
\hline & 56.1 & 56.2 & 56.3 & 56.4 & 56.5 & 55.1 & SB.1 & SB. 2 & SB. 3 & SB.4 & SB.5 \\
\hline ONPG & - & - & - & - & - & - & + & - & - & - & - \\
\hline $\mathrm{ADH}$ & - & + & - & - & + & - & - & - & + & - & - \\
\hline LDC & - & + & - & - & + & - & - & - & + & - & - \\
\hline ODC & + & - & - & - & + & + & + & + & - & - & + \\
\hline CIT & + & + & + & + & + & + & + & + & + & + & + \\
\hline $\mathrm{H}_{2} \mathrm{~S}$ & - & - & - & - & - & - & - & - & - & - & - \\
\hline URE & - & + & - & + & + & - & - & + & + & - & - \\
\hline TDA & - & - & - & - & - & - & - & - & - & - & - \\
\hline IND & - & - & - & - & - & - & - & - & - & - & - \\
\hline VP & - & - & - & - & - & - & - & - & - & - & - \\
\hline GEL & + & + & + & + & + & + & + & + & + & + & + \\
\hline GLU & + & + & + & - & - & + & + & - & - & - & - \\
\hline MAN & + & + & + & - & + & + & + & - & - & - & - \\
\hline INO & - & - & - & - & - & - & - & - & - & - & - \\
\hline SOR & + & - & - & - & + & + & - & + & - & - & + \\
\hline RHA & - & - & - & - & - & - & - & - & - & - & - \\
\hline SAC & + & - & + & - & + & + & + & + & + & - & + \\
\hline MEL & - & - & - & - & - & - & - & - & - & - & - \\
\hline AMY & + & + & + & - & + & + & + & - & - & - & + \\
\hline ARA & - & - & - & - & - & - & - & - & - & - & - \\
\hline $\mathrm{NO}_{2}$ & + & + & + & + & + & + & + & + & + & + & + \\
\hline $\mathrm{N}_{2}$ & - & - & - & - & - & - & - & - & - & - & - \\
\hline
\end{tabular}

Tests: ONPG, $\beta$-galactosidase activity; ADH, Arginine Dihydrolase; LDC, Lysine Decarboxylase; ODC, Ornithine Decarboxylase; CIT, Citrate Utilization; H2S, Hydrogen Sulfide Production; URE, Urease; TDA, Tryptophan Deaminase; IND, Indole Production; VP, Acetoin Production (Voges-Proskaur); GEL, Gelatinase; GLU, Glucose; MAN, Mannitol; INO, Inositol; SOR, Sorbitol; RHA, Rhamnose; SAC, Sucrose; MEL, Melibiose; AMY, Amygdalin; ARA, Arabinose; NO2, Nitrate Reduction to Nitrite; N2, Nitrate Reduction to Nitrogen Gas 
Luis E. Espinoza et al. / OnLine Journal of Biological Sciences 13 (1): 18-27, 2013

Table 3. Interference competition assays amongst the 11 Streptomyces isolates from the Laguna Madre. Each isolate was tested to determine if it could inhibit the growth of another isolate by using an agar overlay inhibition method. Values are the mean of triplicate experiments. Inhibition of other isolates is shown in rows ( 0.00 indicates no inhibition); resistance to other isolates is shown in columns ( 0.00 indicates resistance to inhibition)

\begin{tabular}{|c|c|c|c|c|c|c|c|c|c|c|c|}
\hline Isolate dotted & 56.1 & 56.2 & 56.3 & 56.4 & 56.5 & 55.1 & SB.1 & SB. 2 & SB. 3 & SB.4 & SB. 5 \\
\hline 56.1 & & 0.00 & 0.00 & 0.00 & 0.00 & 0.00 & 0.00 & 0.00 & 0.00 & 0.00 & 0.00 \\
\hline 56.2 & 0.00 & & 0.00 & 0.00 & 0.00 & 0.00 & 0.00 & 0.00 & 0.00 & 0.00 & 0.00 \\
\hline 56.3 & 0.00 & 0.00 & & 0.00 & 0.00 & 0.00 & 0.00 & 0.00 & 0.00 & 0.00 & 0.00 \\
\hline 56.4 & 0.00 & 0.00 & 0.00 & & 0.00 & 0.00 & 0.00 & 0.00 & 0.00 & 0.00 & 0.00 \\
\hline 56.5 & 0.00 & 0.00 & 0.00 & 0.00 & & 0.00 & 0.00 & 0.00 & 0.00 & 0.00 & 0.00 \\
\hline 55.1 & 8.13 & 0.00 & 0.00 & 0.00 & 0.00 & & 0.00 & 0.00 & 0.00 & 0.00 & 0.00 \\
\hline SB.1 & 0.00 & 0.00 & 0.00 & 0.00 & 0.00 & 0.00 & & 0.00 & 0.00 & 0.00 & 0.00 \\
\hline SB. 2 & 0.00 & 0.00 & 0.00 & 0.00 & 0.00 & 0.00 & 0.00 & & 0.00 & 0.00 & 0.00 \\
\hline SB.3 & 0.00 & 0.00 & 0.00 & 0.00 & 0.00 & 0.00 & 6.88 & 0.00 & & 0.00 & 0.00 \\
\hline SB.4 & 9.50 & 0.00 & 0.00 & 0.00 & 12.0 & 0.00 & 0.00 & 0.00 & 0.00 & & 0.00 \\
\hline SB.5 & 0.00 & 0.00 & 0.00 & 0.00 & 0.00 & 0.00 & 0.00 & 0.00 & 0.00 & 0.00 & \\
\hline
\end{tabular}

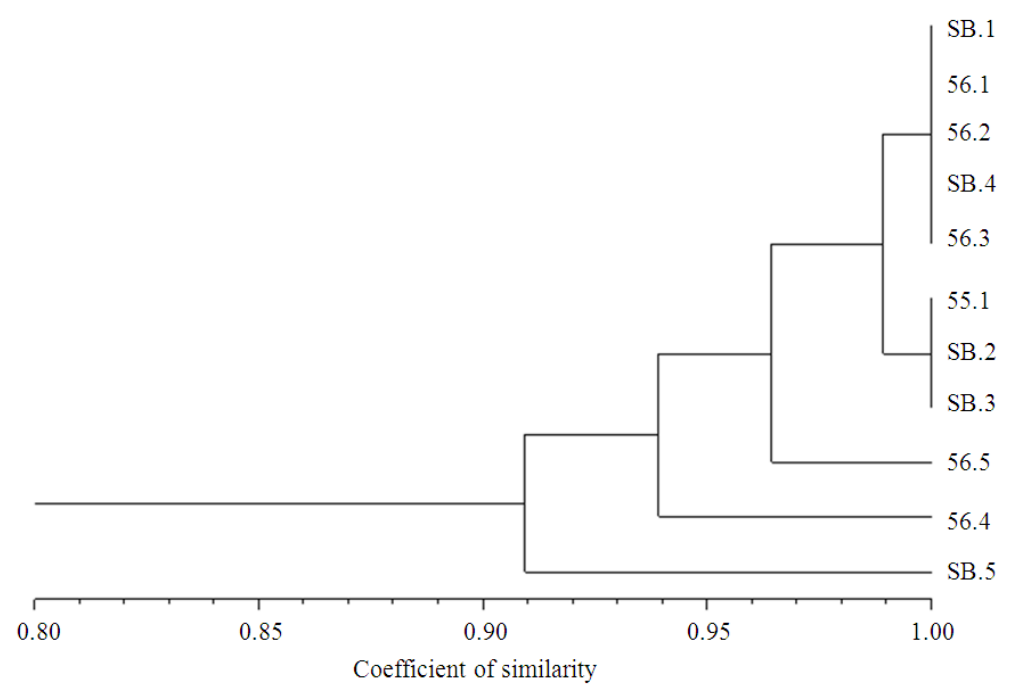

Fig. 3. Similarity of carbon utilization of cultured Streptomyces microorganisms from the Laguna Madre.A total of 95 carbon sources were tested using BIOLOG ${ }^{\mathrm{TM}}$ plates. Based on the number of positive tests and which tests were positive, a carbon utilization profile was created and compared to the profile of all other tested isolates. The similarity coefficient is shown on the $\mathrm{x}$-axis

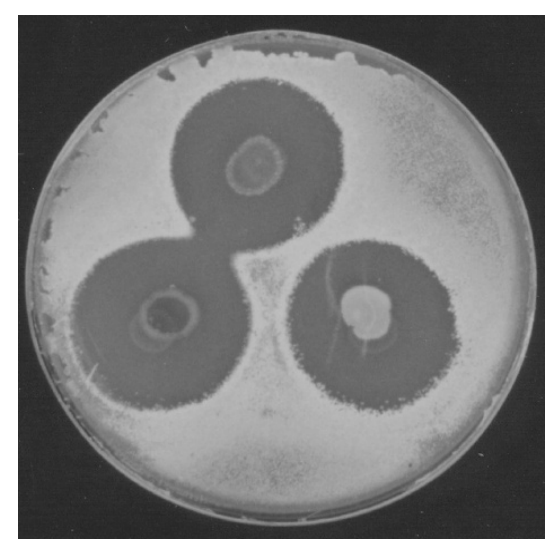

Fig. 4. Representative interference competition plate showing zones of inhibited growth 
Sequencing of the 16S rRNA genes of the 11 isolates revealed that 10 of the isolates were at least a $93 \%$ match to Streptomyces griseus in the BLASTn database (Table 1). Isolate 56.3 most closely matched to Streptomycesscabiei, some strains of which are pathogenic to plants (Healy and Lambert, 1991).

\section{DISCUSSION}

This small pilot study was conducted to ascertain whether the Laguna Madre was a potential habitat of marine Streptomyces species. The Streptomycetaceae have been described in the literature for decades but it has been suggested that aquatic streptomycetes are terrestrial forms that have been washed into freshwater and/or marine environments and that these aquatic streptomycetes are not members of the native microbial community (Cross, 1981). It has also been suggested that Streptomyces inhabiting aquatic ecosystems may not be active but merely surviving in a dormant (e.g., endospore) state. The $\mathrm{pH}$ optima for growth by the Streptomyces we studied would seem to support this notion and suggests that our isolates may be of terrestrial origin. Most of the 11 cultures grew optimally at $\mathrm{pH}$ values that were lower than the water $\mathrm{pH}$ of the Laguna Madre at the time of sampling (see Results) and more closely aligned with the $\mathrm{pH}$ of terrestrial soils (Table 1; Atlas and Bartha, 1998). Several studies have shown the presence of streptomycetes from aquatic environments, including marine near-shore areas and deep sea sediments (Jensen et al., 1991; Moran et al., 1995; Mincer et al., 2002). Despite this, their abundance and activity in hypersaline marine ecosystems, like the Laguna Madre, has been largely neglected.

In this study, 11 Streptomyces isolates out of the tens-of-thousands of microorganisms present in the sediments of the Laguna Madre were cultured. The low number of isolated organisms may be due to ineffective sampling or culturing techniques, or it could indicate that Streptomyces are only minor constituents of the Laguna Madre's sediment microbial community. Given that most of the 11 isolates are presumptively the same or similar species (e.g., Streptomyces griseus) based on 16S rRNA sequencing, it is also possible that the species richness of Streptomyces in the Laguna Madre is limited. Streptomyces griseus is a spore-forming, alkaliphilic bacterium known to produce many types of secondary metabolites, including the antibiotic streptomycin (Liu et al., 2005). However, the results of the $16 \mathrm{~S}$ rRNA gene sequencing should only be considered putative. There are a limited number of complete bacterial sequences in the BLASTn database and none of the isolates was a $100 \%$ match for known sequenced Streptomyces strains. As more sequences are added to the database, better identification of the organisms will become possible.

Despite the small number of isolates and their $16 \mathrm{~S}$ rRNA gene similarity, the 11 Streptomyces display some diverse characteristics with regards to their biochemical profiles and carbon source utilization. Ten of the 11 isolates had distinct profiles when assayed with API $20 \mathrm{E}^{\circledR}$ strips and all could utilize a range of organic carbon substrates in BIOLOG ${ }^{\mathrm{TM}}$ assays. Many of the 11 isolates had identical BIOLOG ${ }^{\mathrm{TM}}$ profiles because they gave positive results for all 95 substrates tested (isolates $56.1,56.2,56.3$, SB.1 and SB.4) or 94 out of 95 substrates tested (isolates 55.1, SB.2, SB.3). Despite this, the lack of correspondence between $\mathrm{API}^{\circledR}$ and BIOLOG $^{\mathrm{TM}}$ phenotypes (Mantel's test) shows some diverse characteristics among this collection of isolates and suggests that utilizing both measures of physiological diversity provides independent information on isolate phenotype. The Streptomyces isolates also displayed a strong halotolerance, which would be necessary for survival in the hypersaline Laguna Madre and some isolates were able to inhibit the growth of others. Thus, although Streptomyces in the Laguna Madre may be a small population of phylogentically similar organisms, they are phenotypically and physiologically varied. This result of lack of correspondence between genetic identity and phenotype is consistent with other studies of soil bacteria in terrestrial systems (Bronstad et al., 1996; Bramwell et al., 1998; Davelos et al., 2004b).

\section{CONCLUSION}

Based on the results of this small project, a further investigation of Streptomyces in the Laguna Madre is warranted to gain a greater understanding of the density, activity and diversity of these organisms in this and other hypersaline environments, which may be a reservoir of novel microorganisms and their secondary metabolites.

\section{ACKNOWLEDGEMENTS}

We wish to thank Dr. Hudson DeYoe and the UTPA Coastal Studies Lab for assistance in sample collection and Thomas M. Eubanks for assistance in DNA sequencing. Funding was provided by the Louis Stokes Alliance for Minority Participation (LSAMP) program at UTPA. 


\section{REFERENCES}

Altschul, S.F., T.L. Madden, A.A. Schaffer, J. Zhang and Z. Zhang et al., 1997. Gapped BLAST and PSIBLAST: A new generation of protein database search programs. Nucl. Acid Res., 25: 3389-3402. DOI: $10.1093 /$ nar/25.17.3389

Anderson, A.S. and E.M.H. Wellington, 2001. The taxonomy of streptomyces and related genera. Int. J. Systematic Evol. Microbiol., 51: 797-814. DOI: 10.1099/00207713-51-3-797

Atlas, R.M. and R. Bartha, 1998. Microbial Ecology: Fundamentals and Applications. 4th Edn., Pearson Education, India, ISBN-10: 8131713849, pp: 704.

Barton, L.L. and D.E. Northrup, 2011. Microbial Ecology. 1st Edn. John Wiley and Sons, Oxford, ISBN-10: 1118015835, pp: 360.

Bowers, J.H., L.L. Kinkel, R.K. Jones and N.A. Anderson, 1996. Influence of disease suppressive strains of Streptomyces on the native Streptomyces community in soil as determined by the analysis of cellular fatty acids. Canadian J. Microbiol., 42: 2737. DOI: $10.1139 / \mathrm{m} 96-005$

Bramwell, P.A., P. Wiener, A.D.L. Akkermans and E.M.H. Wellington, 1998. Phenotypic, genotypic and pathogenic variation among streptomycetes implicated in common scab disease. Lett. Applied Microbiol., 27: 255-260. DOI: 10.1046/j.1472765X.1998.00439.x

Bronstad, K., K. Dronen, L. Oyvreas and V. Torsvik, 1996. Phenotypic diversity and antibiotic resistance in soil bacterial communities. J. Ind. Microbiol., 17: 253-259. DOI: 10.1007/BF01574699

Cross, T., 1981. Aquatic actinomycetes: A critical survey of the occurrence, growth and role of actinomycetes in aquatic habitats. J. Applied Microbiol., 50: 397423. DOI: 10.1111/j.1365-2672.1981.tb04245.x

Davelos, A.L, K. Xiao, J.M. Flor and L.L. Kinkel, 2004b. Genetic and phenotypic traits of streptomycetes used to characterize antibiotic activities of field-collected microbes. Canadian J. Microbiol., 50: 79-89. DOI: 10.1139/w03-107

Davelos, A.L., L.L. Kinkel and D.A. Samac, 2004a. Spatial variation in the frequency and intensity of antibiotic interactions among streptomycetes from prairie soil. Applied Environ. Microbiol., 70: 10511058. DOI: 10.1128/AEM.70.2.1051-1058.2004

Healy, F.G. and D.H. Lambert, 1991. Relationships among Streptomyces spp. causing potato scab. Int. J. Systematic Bacteriol., 41: 479-482. DOI: 10.1099/00207713-41-4-479
Jensen, P.R., R. Dwight and W. Fenical, 1991. Distribution of actinomycetes in near-shore tropical marine sediments. Applied Environ. Microbiol., 57: 1102-1108.

Kuster, E. and S.T. Williams, 1964. Selection of media for isolation of streptomycetes. Nature, 202: 928929. DOI: $10.1038 / 202928 \mathrm{a} 0$

Liu, Z., Y. Shi, Y. Zhang, Z. Zhou and Z. Lu et al., 2005. Classification of Streptomyces griseus (Krainsky 1914) Waksman and Henrici 1948 and related species and the transfer of 'Microstreptospora cinerea' to the genus Streptomyces as Streptomyces yanii sp. nov. Int. J. Syst. Evol. Microbiol., 55: 1605-1610. DOI: 10.1099/ijs.0.63654-0

Madigan, M.T., J.M. Martinko and J. Parker, 2000. Brock Biology of Microorganisms. 9th Edn., Prentice Hall, Upper Saddle River, New Jersey, ISBN-10: 0130819220, pp: 991.

Malkawi, H.I., I. Saadoun, F.A. Moumani and M.M. Meqdam, 1999. Use of RAPD-PCR fingerprinting to detect genetic diversity of soil streptomyces isolates. New Microbiol., 22: 53-58. PMID: 10190117

Mincer, T.J., P.R. Jensen, C.A. Kauffman and W. Fenical, 2002. Widespread and persistent populations of a major new marine actinomycete taxon in ocean sediments. Applied Environ. Microbiol., 68: 5005-5011. DOI: 10.1128/AEM.68.10.5005-5011.2002

Moran, M.A., L.T. Rutherford and R.S. Hodson, 1995. Evidence for indigenous Streptomyces populations in a marine environment determined with a $16 \mathrm{~S}$ rRNA Probe. Applied Environ. Microbiol., 61: 3695-3700. PMID: 7487005

Rheinheimer, G., 1992. Aquatic Microbiology. 4th Edn., John Wiley and Sons, New York, ISBN-10: 0471926957, pp: 363.

Sambrook, J. and D.W. Russell, 2001. Molecular Cloning: A Laboratory Manual. 3rd Edn., Cold Spring Harbor Laboratory Press, Cold Spring Harbor, New York, ISBN-10: 0879695773.

Takeuchi, T., H.F. Sawada, F. Tanaka and I. Matsuda, 1996. Phylogenetic analysis of streptomyces spp. causing potato scab based on 16S rRNA sequences. Int. J. Syst. Bacteriol., 46: 476-479. DOI: 10.1099/00207713-46-2-476

Tunnell, J.W. and F.W. Judd, 2002. The Laguna Madre of Texas and Tamaulipas. 1st Edn., Texas A\&M University Press, College Station, TX, ISBN-10: 1585441333, pp: 346. 
Vahjen, W., J.C. Munch and C.C. Tebbe, 1995. Carbon source utilization of soil extracted microorganisms as a tool to detect the effects of soil supplemented with genetically engineered and non-engineered corynebacterium glutamicum and a recombinant peptide at the community level. FEMS Microbiol. Ecol., 18: 317-328. DOI: $0.1111 /$ j.15746941.1995.tb00188.x
Zak, J.C., M.R. Willig, D.L. Moorehead and H.G. Wildman, 1994. Functional diversity of microbial communities: A quantitative approach. Soil Biol. Biochem., 26: 1101-1108. DOI: 10.1016/00380717(94)90131-7 